\title{
Construct Validity and Measurement Invariance of Computerized Adaptive Testing: Application to Measures of Academic Progress (MAP) Using Confirmatory Factor Analysis
}

\author{
Shudong Wang ${ }^{1}$, Marty McCall ${ }^{2}$, Hong Jiao ${ }^{3} \&$ Gregg Harris $^{1}$ \\ ${ }^{1}$ Department of Education Research, NWEA, USA \\ ${ }^{2}$ Smarter Balanced Assessment Consortium, USA \\ 3 Department of Human Development and Quantitative Methodology, University of Maryland, USA \\ Correspondence: Shudong Wang, 121 NW Everett Street, Portland, OR 97209, USA. Tel: 1-503-548-5142. \\ E-mail: Shudong.wang@NWEA.org
}

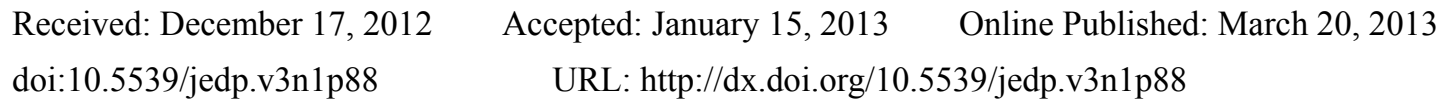

\begin{abstract}
The purpose of this study is twofold. The first is to investigate the construct or factorial structure of a set of Reading and Mathematics computerized adaptive tests (CAT), Measures of Academic Progress (MAP), given in different states at different grades and academic terms. The second purpose is to investigate the invariance of test factorial structure across different grades, academic terms, and states. Because of the uniqueness of CAT data (different students receive different items), traditional factor analysis based on fixed form data is no longer practically possible at the item level. This study illustrates how to overcome the difficulty of applying factor analysis in CAT data and study results provide evidence for valid interpretation of MAP tests scores across grades at different academic terms for different states.
\end{abstract}

Keywords: achievement, construct, computerized adaptive tests, factor analysis, Measures of Academic Progress

\section{Introduction}

The purpose of this study is twofold: first, to investigate the construct or factorial structure of CAT MAP Reading and Mathematics tests at different grades, academic terms, and states; second, to investigate the invariance of test factorial structure across different grades, academic terms and states. Recently, computerized adaptive testing (CAT) has been seen as a particularly effective method of measuring an individual student's status and growth over time in K-12 assessment (Way, Twing, Camara, Sweeney, Lazer, \& Mazzeo, 2010). The major reason is that CAT has advantages over traditional paper-pencil tests, such as shorter length, immediate feedback on student scores, better reliability, and accuracy (Lord, 1977; Kingsbury \& Weiss, 1983; Steinberg, \& Thissen, 1990). Its unique advantages in K-12 assessment include cost savings, multiple testing opportunities for formative and interim assessments, and better validity (Way, 2006).

Right now, Oregon, Delaware, and Idaho use CAT in their state assessments, and several other states (Georgia, Hawaii, Maryland, North Carolina, South Dakota, Utah, and Virginia) are in various stages of CAT development. As a matter of fact, one of the two consortia created as part of the Race to the Top initiative, the SMARTER Balanced Assessment Consortium (SBAC) consisting of over half of the states, is committed to a computerized adaptive model because it represents a unique opportunity to create a large-scale assessment system that provides maximally accurate achievement results for each student (Race to the Top Assessment Program, 2010).

Because high stakes decisions about students are based on state test results, these tests should be evaluated using professional testing principles, such as validity and reliability. Validity (and fairness), according to the Standards for Educational and Psychological Testing (AERA, APA, NCME, 1999), is the most important consideration in test development and evaluation.

The MAP Reading and Mathematics tests, like most CATs, use a unidimensional item response theory (IRT) model based on the premise that correlations among responses to test questions can be explained by a single underlying trait. Traits like reading and math are obviously complex, representing many component skills and 
facts combined in specific ways. The claim of unidimensionality is that these components work together to manifest a coherent whole. Although tests are often structured around goal areas, this is done to provide adequate domain sampling rather than to measure different traits. While individuals may have strengths and weaknesses in goal areas on a unidimensional test, any systematic relationship among goals should be explained by the effect of the unitary latent trait on item responses.

Detecting dimensionality in adaptive assessments is tricky. Because of the uniqueness of CAT tests (different persons respond to different items), conducting factor analysis is more challenging for CAT data than for linear or fixed form data.

First of all, there are no common test forms, so data are very sparse. Observable (manifest) item variables differ across persons for both the overall test event and at the cluster (goal or subtest) level. So, although goal score variables are the same, the context differs; i.e. subtest scores are derived from different sets of items. One possible solution is to conduct confirmatory factor analysis (CFA) on the entire item bank, but the large amount of missing data (typically, the missing rate is above $90 \%$ if the ratio of test length to item bank size is 20 ) makes this unwieldy. For MAP Reading and Mathematics tests, typical missing rates are around $98 \%$ because the ratio of test length to item bank counts is around 50. The common imputation methods (Rubin, 1987) may statistically help the missing issue, but are difficult to execute.

The second issue is that the adaptive algorithm operates on the assumption of local independence (LI), thus restricting covariance among items. Items are selected to maximize information at the estimated latent trait level so that for dichotomous items the probability of a correct answer is about .5, responses are randomly distributed, and item covariance is low. Since the goal of factor analysis is to summarize patterns of correlation among observed variables, this restriction may lead to singularly uninformative factor analysis results for CATs. McCall and Hauser (2006) used Yen's (1984) Q statistic to get around the sparse data problem. The Q statistic operates on pairwise relationships between items and looks for covariance unexplained by the observed score. Because item selection is conditioned on the momentary achievement estimate, the range of ability is restricted, thus limiting variance and covariance. Values of the $\mathrm{Q}$ statistic were so small compared to those for fixed form tests that they were difficult to interpret.

One way to get around the sparse data problem is to conduct CFA at the item cluster level (goal or sub-content level). Since items in each CAT test event are balanced among goal areas based on content specifications, a reasonable option may be to assume that items within each goal area are content homogeneous across persons and that goal scores may be used as observable variables. This is the method used here. If multiple traits based on goal areas explain item responses, this might show up as differential factor loading of the goal scores on the overall score. Furthermore, patterns of factor loading might differ with the different goal structures used in different states or among grades within the same state. For illustration purpose only, Figure 1

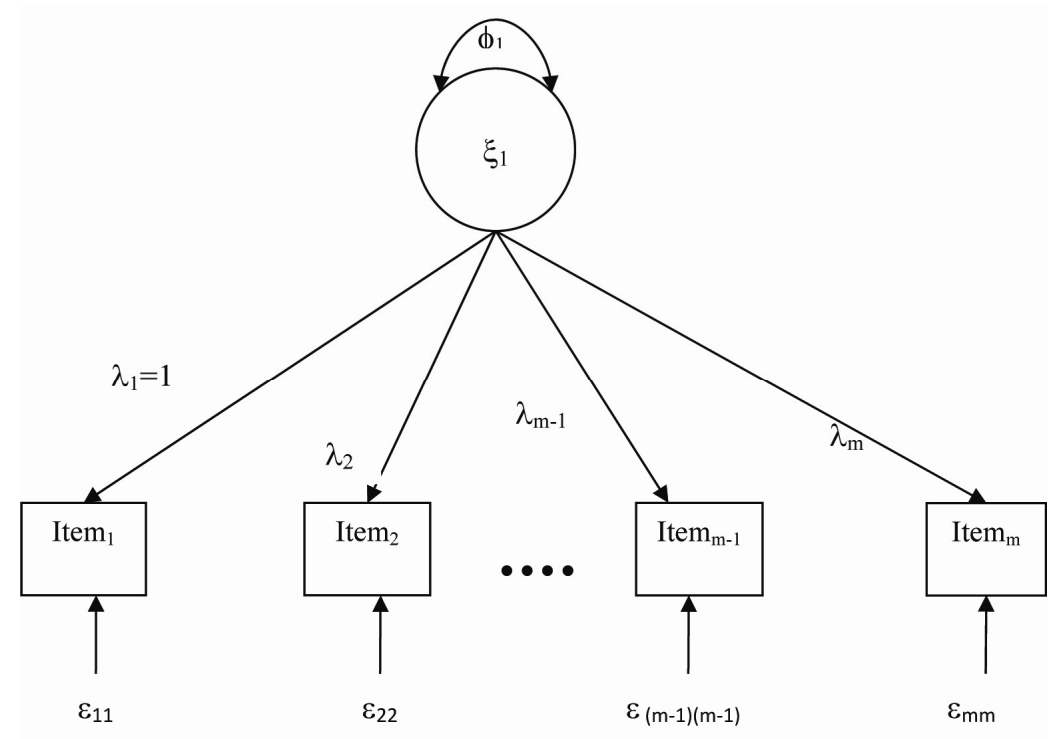

Figure 1. Individual item as observables 


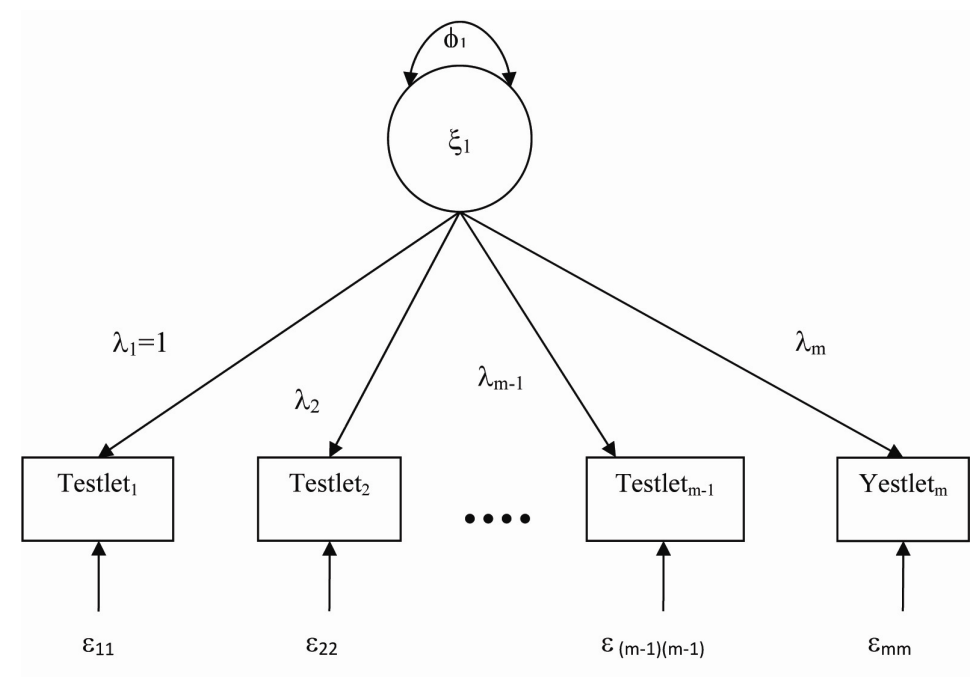

Figure 2. Testlets as observable variables

Figure 1 shows the factor model under the IRT assumption of LI. This is the model that is difficult to test with computerized adaptive test data. Figure 2 shows a factor model that uses testlet, goal score, or item clusters as observable variables. At the testlet level, this model still satisfies the LI assumption, but the LI assumption might or might not hold at the individual item level.

\section{Methods}

\subsection{Data Source and Participants}

All data used in this study were collected from MAP Reading and Mathematics tests administered from Spring 2009 to Spring 2011 twice during the academic year. The MAP tests were used with grade 3 to grade 9 across 50 states. The data for this study focuses on 10 states (Colorado, Illinois, Indiana, Kansas, Kentucky, Michigan, Minnesota, South Carolina, Washington, and Wisconsin) that have the largest MAP sample sizes among the 50 states. Reading and Mathematics sample sizes for each state are presented in Table 1. Samples were collected for five academic terms: Spring 2009, Fall 2009, Spring 2010, Fall 2010, and Spring 2011. For each academic term, the samples contained results from five grades, with the grade range depending on the academic term.

Table 1. Sample sizes for MAP reading and mathematics tests across states

\begin{tabular}{lll}
\hline State Name & Reading & Mathematics \\
\hline Colorado & 256,310 & 259,600 \\
Illinois & 444,485 & 433,595 \\
Indiana & 262,740 & 247,905 \\
Kansas & 217,730 & 211,070 \\
Kentucky & 149,785 & 148,725 \\
Michigan & 150,945 & 151,645 \\
Minnesota & 457,630 & 448,470 \\
South Carolina & 473,135 & 465,525 \\
Washington & 316,980 & 316,925 \\
Wisconsin & 351,740 & 351,690 \\
\hline
\end{tabular}

Tables 2 and 3 (due to the limited space, can't list 10 state tables) list the frequency and percentages of samples across grades and terms for the Illinois Mathematics test and South Carolina Reading test. For each state, samples were randomly drawn from state records. Approximately $20 \%$ of students for each state were selected 
under the constraints that student has to have scores for five academic terms and is in the grade range of 3 to 9 in the first term.

Table 2. Frequency and percentages of samples across grades and academic calendars for Illinois MAP mathematics test

\begin{tabular}{lllllll}
\hline Grade & Spring 2009 & Fall 2009 & Spring 2010 & Fall 2010 & Spring 2011 & Total \\
\hline 3 & 20000 & & & & 20000 \\
& $(4.61)$ & & & & $(4.61)$ \\
4 & 20000 & 20000 & 20000 & & & 60000 \\
& $(4.61)$ & $(4.61)$ & $(4.61)$ & & & $(13.84)$ \\
5 & 20000 & 20000 & 20000 & 20000 & 20000 & 100000 \\
& $(4.61)$ & $(4.61)$ & $(4.61)$ & $(4.61)$ & $(4.61)$ & $(23.06)$ \\
6 & 20000 & 20000 & 20000 & 20000 & 20000 & 100000 \\
& $(4.61)$ & $(4.61)$ & $(4.61)$ & $(4.61)$ & $(4.61)$ & $(23.06)$ \\
7 & 6719 & 20000 & 20000 & 20000 & 20000 & 86719 \\
& $(1.55)$ & $(4.61)$ & $(4.61)$ & $(4.61)$ & $(4.61)$ & $(20.00)$ \\
8 & & 6719 & 6719 & 20000 & 20000 & 53438 \\
& & $(1.55)$ & $(1.55)$ & $(4.61)$ & $(4.61)$ & $(12.32$ \\
9 & & & 6719 & 6719 & 13438 \\
& & & & $(1.55)$ & $(1.55)$ & $(3.10)$ \\
Total & 86719 & 86719 & 86719 & 86719 & 86719 & 433595 \\
& $(20.00$ & $(20.00)$ & $(20.00)$ & $(20.00)$ & $(20.00)$ & $(100.00)$ \\
\hline
\end{tabular}

Note. Percentage in parentheses

Table 3. Frequency and percentages of samples across grades and academic calendars for South Carolina MAP reading test

\begin{tabular}{lllllll}
\hline Grade & Spring 2009 & Fall 2009 & Spring 2010 & Fall 2010 & Spring 2011 & Total \\
\hline 3 & 20000 & & & & 20000 \\
& $(4.23)$ & & & & $(4.23)$ \\
4 & 20000 & 20000 & 20000 & & & 60000 \\
& $(4.23)$ & $(4.23)$ & $(4.23)$ & & & $(12.68)$ \\
5 & 20000 & 20000 & 20000 & 20000 & 20000 & 100000 \\
& $(4.23)$ & $(4.23)$ & $(4.23)$ & $(4.23)$ & $(4.23)$ & $(21.14)$ \\
6 & 20000 & 20000 & 20000 & 20000 & 20000 & 100000 \\
& $(4.23)$ & $(4.23)$ & $(4.23)$ & $(4.23)$ & $(4.23)$ & $(21.14)$ \\
7 & 14627 & 20000 & 20000 & 20000 & 20000 & 94627 \\
& $(3.09)$ & $(4.23)$ & $(4.23)$ & $(4.23)$ & $(4.23)$ & $(20.00)$ \\
8 & & 14627 & 14627 & 20000 & 20000 & 69254 \\
& & $(3.09)$ & $(3.09)$ & $(4.23)$ & $(4.23)$ & $(14.64)$ \\
9 & & & 14627 & 14627 & 29254 \\
& & & $(3.09)$ & $(3.09)$ & $(6.18)$ \\
Total & 94627 & 94627 & 94627 & 94627 & 94627 & 473135 \\
& $(20.00$ & $(20.00)$ & $(20.00)$ & $(20.00)$ & $(20.00)$ & $(100.00)$ \\
\hline
\end{tabular}

Note. Percentage in parentheses 


\subsection{Instruments}

The MAP tests of Reading and Mathematics for grades 3 to 9 were used in this study. MAP tests are computerized adaptive assessments that have been published by Northwest Evaluation Association (NWEA) since 2000. The purpose of MAP tests is to provide educators with information to inform teaching and learning in Reading, Mathematics, and Science (NWEA, 2011). In general, the MAP Reading test consists of 40 multiple-choice items with four options and the MAP Mathematics test includes 50 multiple-choice items with four or five options. Because content validity is one of the most important sources of evidence of test validity in achievement tests, in NWEA item development, all items match the assessable sections of a set of academic content standards both in breadth of content and depth of knowledge. In general, the MAP reading test comprises four goals: Word Meaning, Literal Comprehension, Interpretive Comprehension, and Evaluative Comprehension; the MAP mathematics test consists of seven goals: Number/Numeration Systems, Operations/Computation, Equations/Numerals, Geometry, Measurement, Problem Solving, Statistics/Probability, and Applications.

For each state, the MAP tests are aligned to specific state content standards by assembling pools of items that address state content standards. Test algorithms survey the pools within goal or strand areas to assure domain coverage. Table 4 lists test length (fixed length CAT) and numbers of goals (subtests) of both Reading and Mathematics tests. The examples of content specifications for Colorado Reading and Indiana Mathematics are shown in Table 5.

Table 4. Test length and numbers of goals of reading and Mathematics tests for grades 3 to 9 across states

\begin{tabular}{lllll}
\hline \multirow{2}{*}{ State Name } & \multicolumn{3}{l}{ Reading } & Mathematics \\
\cline { 2 - 5 } & Test Length & Number of Goals & Test Length & Number of Goals \\
\hline Colorado & 40 & 4 & 50 & 6 \\
Illinois & 40 & 4 & 50 & 5 \\
Indiana & 40 & 5 & 50 & 7 \\
Kansas & 40 & 5 & 50 & 4 \\
Kentucky & 40 & 5 & 50 & 5 \\
Michigan & 40 & 4 & 50 & 6 \\
Minnesota & 40 & 4 & 50 & 4 \\
South Carolina & 40 & 3 & 50 & 5 \\
Washington & 40 & 5 & 50 & 4 \\
Wisconsin & 40 & 4 & 50 & 5 \\
\hline
\end{tabular}

Table 5. Content Specifications of Colorado Reading and Indiana Mathematics for Grades 3 to 9

\begin{tabular}{llll}
\hline $\begin{array}{l}\text { Colorado Reading } \\
\text { Goals }\end{array}$ & $\%$ items & Goals & $\%$ items \\
\hline Reading Strategies, Comprehending Literary & $25 \%$ & Number Sense & \\
Texts & & Computation & $14 \%$ \\
Comprehending Informative, Persuasive Texts & $25 \%$ & Algebra and Functions & $14 \%$ \\
Word Relationships and Meanings & $25 \%$ & Geometry & $14 \%$ \\
Total operational items & $25 \%$ & Measurement & $14 \%$ \\
& & Statistics, Data Analysis, Probability & $14 \%$ \\
& & Problem Solving & $14 \%$ \\
\hline
\end{tabular}

The marginal reliabilities of tests across 50 states and grades are consistently in the low to mid 0.90 's (NWEA, 2011). Because items selected during the CAT test for each student are based on the student's provisional ability, these items have a limited range of difficulty for a given test taker. However, all items administered to each student have to satisfy the content requirements of the test to insure content validity and domain coverage. 


\subsection{Data Analysis}

Using Proc TCALIS in SAS ${ }^{\circledR} 9.2$ (SAS Institute Inc., 2008), both confirmatory factor analysis (CFA) and multi-group confirmatory factor analysis (MGCFA) were conducted to determine the adequacy of fit of the factor structures of MAP tests and invariance of factor models across grades and academic terms (invariance across terms were not statistically tested). All estimation in this study uses the maximum likelihood method.

All MAP tests assume there is only one latent factor (student achievement) that accounts for covariance among observed variables at item or item cluster levels. All MAP tests were scaled based on unidimensional Rasch model (Rasch, 1980) and RIT (Rasch unIT) scale that is linearly transformed from logit (RIT $=\operatorname{logit} x 10+200$, NWEA, 2011). The general rationale on choice of Rasch model over other more complex item response models for dichotomous response is that Rasch model has unique properties over other models. These properties include sufficiency, separability, specific objectivity, latent additivity (Wright \& Stone, 1979; Embretson \& Reise, 2000). According to Wilson (2003), the general criteria used for choose a measurement model is to preserve the interpretability of the construct map and the models must preserve the order of items throughout the range of person locations, and must do so in a way that is consistent with the interpretational requirements of the map. Rasch model fit the criteria and the data. Figure 3 present CFA and MGCFA models of MAP tests and the detailed information of the represented models can be found in papers of McArdle (1988) and McDonald (1985).

The one-factor model with goal scores (or subtests) as observed variables and CFA was used to evaluate the adequacy of model to fully account for the relationships among subtests. Once adequacy of model fit was determined, MGCFA was used to test whether the same model holds across different groups. According to Steenkamp and Baumgarther (1998), the invariance of factor loadings is sufficient for construct comparability across groups. In this study, the additional condition of invariance of factor variance was also tested. Three levels of invariance across 5 grades at each of the academic calendars tested are no constraint (NC), equal factor loading (L), and equal factor loadings and factor variances (LV, see Appendix A).

Several well-known goodness-of-fit indexes (GOF) were used to evaluate model fit: (1) absolute indexes that include chi-square $\chi^{2}$, unadjusted goodness-of-fit indexes (GFI), and standardized root mean square residual (SRMR); (2) incremental indexes that include the comparative fit index (CFI) and Bentler-Bonett normal fit index (NFI); (3) parsimony index, the root mean square error of approximation (RMSEA). For group comparisons with increased constraints, the $\chi^{2}$ value provides the basis of comparison with the previously fitted model, although $\chi^{2}$ is not considered as the best practice because it is sample size dependent. A non-significant difference in $\chi^{2}$ values between nested models reveals that all equality constraints hold across the groups. Therefore, the measurement model remains invariant across groups as the constraints are increased. A significant $\chi^{2}$ does not necessarily indicate a departure from invariance when the sample size is large. Hu and Bentler (1999) recommended using combinations of GOF indices to obtain a robust evaluation of data-model fit in structural equation modeling. The cutoff criterion values of good model fit they recommended are CFI, GFI, NFI $>0.95$, RMSEA $<0.06$, and SRMR $<0.08$. It is worth to note that many researchers (March 2007a, Marsh, Hau, \& Grayson, 2005) showed that GOF criteria from Hu and Bentler (1999) are too restrictive.

\section{Results}

\subsection{Results of CFA}

Tables 6 and 7 present the summaries of GOF indexes for independent models of Washington MAP Reading and South Carolina MAP Mathematics tests for by grade and term (because of limited space, only partial results are listed for two of 10 states). Although not shown in the table, all factor loadings of models across content, grades, and states are statistically significant. There are mixed results on the statistically significant $\chi^{2}$ tests (Washington Reading tests are not significant and South Carolina Mathematics are significant) and very similar patterns of $\chi^{2}$ tests results hold for the rest of the states tests. However, given the large sample sizes across states, it is not surprising to have statistically significant $\chi^{2}$ tests results for some states.

All values of fit indexes (except RMSEAs for Michigan MAP Mathematics tests) satisfy the Hu and Bentler (1999) criteria and show that each model fits data extremely well for different content areas, grades, terms, and states. Overall results suggest that the one-factor (unidimensional) model is the most reasonable model for MAP tests in these 10 states. 


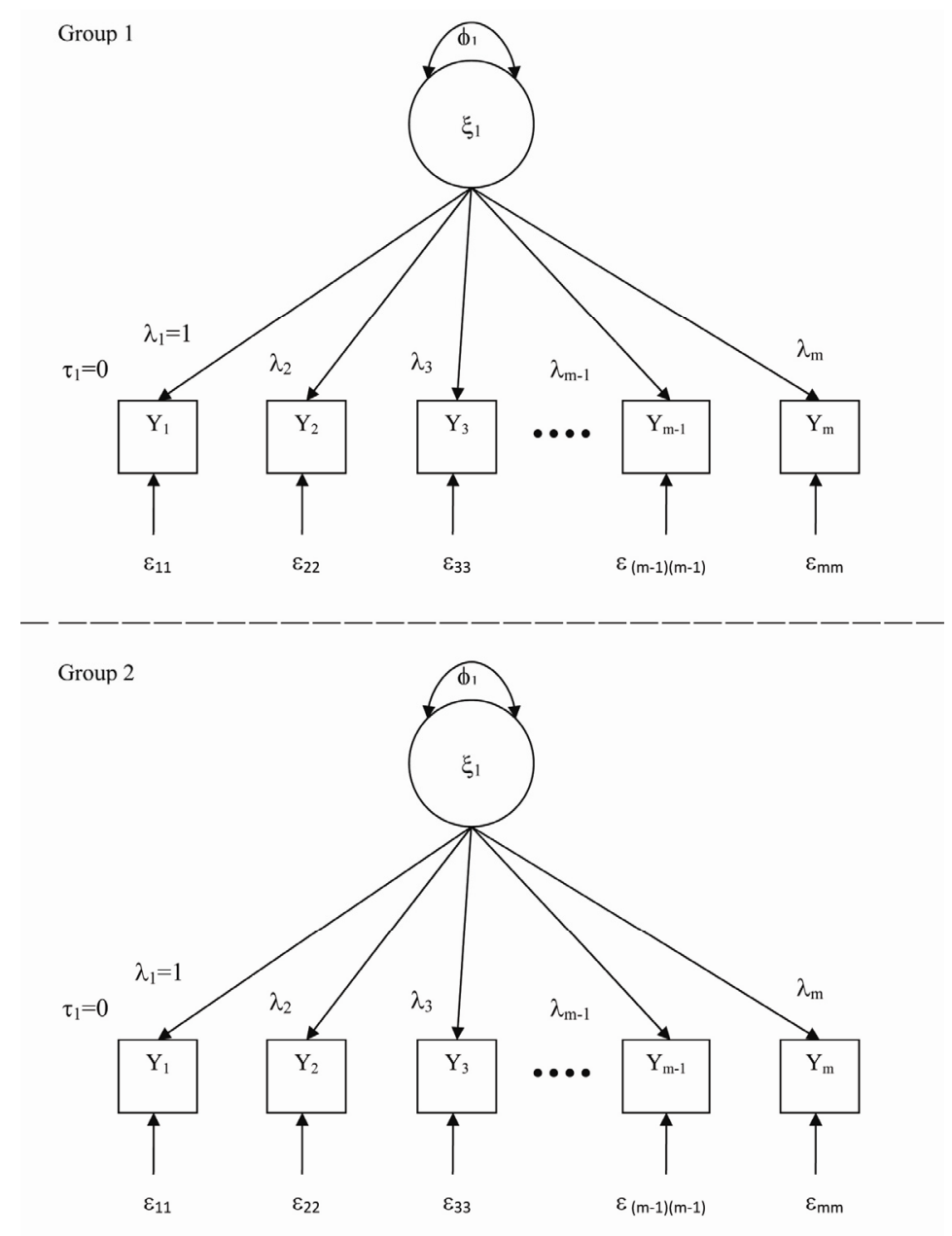

Figure 3. Models of MAP tests across groups (group indicators omitted for simplicity)

\subsection{Results of MGCFA}

Tables 8 and 9 display the summaries of GOF indexes of the nested models that tested for measurement invariance across grades for Kansas MAP Reading and Michigan Mathematics Tests. In the nested model comparison, the effect of constraints (NC, L, and LV) imposed on less restricted modes can be evaluated by using the difference between $\chi^{2}$ (called $\Delta \chi^{2}$ ) because it is distributed as $\chi^{2}$ with the degree of freedom equal to the difference in degrees of freedom between the two models. The null hypothesis of no significant difference in fit is tested by evaluating whether the chi-square difference is significant. If the difference is significant, then the null hypothesis is rejected (Loehlin, 2004). However, the $\chi 2$ test may be misleading because (1) the more complex the model, the more likely a good fit, (2) the larger the sample size, the more likely the rejection of the model and the more likely a Type II error, and (3) the chi-square fit index is also very sensitive to violations of the assumption of multivariate normality. To address these limitations, the difference of other GOF (CFI, GFI, NFI, RMSEA, and SRMR) as adjuncts to the $\chi^{2}$ statistic can also be used to assess model fit. For the Kansas MAP Reading Tests (see Table 8$), \chi 2$ increases $(\Delta \chi 2)$ are significant for testing $\mathrm{L}$ invariance at different terms, but not significant for testing LV invariance. The rest of the states' results show a similar pattern. For Michigan Mathematics Tests, all $\chi^{2}$ increases are significant for both $L$ and LV invariance. 
Table 6. Summary of goodness-of- fit indexes of models of Washington MAP reading tests for each grade at each academic calendar

\begin{tabular}{|c|c|c|c|c|c|c|c|c|c|}
\hline Academic Calendar & Grade & $\mathrm{N}$ & $\chi^{2}$ & $\mathrm{df}$ & CFI & GFI & NFI & RMSEA & SRMR \\
\hline Spring & 3 & 12,795 & 24.94 & 5 & 1.00 & 1.00 & 1.00 & 0.02 & 0.00 \\
\hline \multirow[t]{4}{*}{2009} & 4 & 13,296 & 7.19 & 5 & 1.00 & 1.00 & 1.00 & 0.01 & 0.00 \\
\hline & 5 & 12,957 & 9.11 & 5 & 1.00 & 1.00 & 1.00 & 0.01 & 0.00 \\
\hline & 6 & 14,285 & 7.98 & 5 & 1.00 & 1.00 & 1.00 & 0.01 & 0.00 \\
\hline & 7 & 10,065 & 3.33 & 5 & 1.00 & 1.00 & 1.00 & 0.00 & 0.00 \\
\hline Fall & 4 & 12,795 & 10.07 & 5 & 1.00 & 1.00 & 1.00 & 0.01 & 0.00 \\
\hline \multirow[t]{4}{*}{2009} & 5 & 13,296 & 15.13 & 5 & 1.00 & 1.00 & 1.00 & 0.01 & 0.00 \\
\hline & 6 & 12,957 & 12.55 & 5 & 1.00 & 1.00 & 1.00 & 0.01 & 0.00 \\
\hline & 7 & 14,285 & 15.06 & 5 & 1.00 & 1.00 & 1.00 & 0.01 & 0.00 \\
\hline & 8 & 10,065 & 6.52 & 5 & 1.00 & 1.00 & 1.00 & 0.00 & 0.00 \\
\hline Spring & 4 & 12,795 & 17.56 & 5 & 1.00 & 1.00 & 1.00 & 0.01 & 0.00 \\
\hline \multirow[t]{4}{*}{2010} & 5 & 13,296 & 19.52 & 5 & 1.00 & 1.00 & 1.00 & 0.01 & 0.00 \\
\hline & 6 & 12,957 & 10.78 & 5 & 1.00 & 1.00 & 1.00 & 0.00 & 0.00 \\
\hline & 7 & 14,285 & 5.72 & 5 & 1.00 & 1.00 & 1.00 & 0.00 & 0.00 \\
\hline & 8 & 10,065 & 7.29 & 5 & 1.00 & 1.00 & 1.00 & 0.00 & 0.00 \\
\hline Fall & 5 & 12,795 & 15.39 & 5 & 1.00 & 1.00 & 1.00 & 0.01 & 0.00 \\
\hline \multirow[t]{4}{*}{2010} & 6 & 13,296 & 5.28 & 5 & 1.00 & 1.00 & 1.00 & 0.00 & 0.00 \\
\hline & 7 & 12,957 & 11.66 & 5 & 1.00 & 1.00 & 1.00 & 0.01 & 0.00 \\
\hline & 8 & 14,285 & 18.77 & 5 & 1.00 & 1.00 & 1.00 & 0.01 & 0.00 \\
\hline & 9 & 10,065 & 6.06 & 5 & 1.00 & 1.00 & 1.00 & 0.00 & 0.00 \\
\hline Spring & 5 & 12,795 & 4.4 & 5 & 1.00 & 1.00 & 1.00 & 0.00 & 0.00 \\
\hline \multirow[t]{4}{*}{2011} & 6 & 13,296 & 10.63 & 5 & 1.00 & 1.00 & 1.00 & 0.01 & 0.00 \\
\hline & 7 & 12,957 & 15.08 & 5 & 1.00 & 1.00 & 1.00 & 0.01 & 0.00 \\
\hline & 8 & 14,285 & 13.90 & 5 & 1.00 & 1.00 & 1.00 & 0.01 & 0.00 \\
\hline & 9 & 10,065 & 4.52 & 5 & 1.00 & 1.00 & 1.00 & 0.00 & 0.00 \\
\hline
\end{tabular}


Table 7. Summary of goodness-of-fit indexes of models of South Carolina MAP Mathematics tests for each grade at each academic calendar

\begin{tabular}{|c|c|c|c|c|c|c|c|c|c|}
\hline $\begin{array}{l}\text { Academic } \\
\text { Calendar }\end{array}$ & Grade & $\mathrm{N}$ & $\chi^{2}$ & $\mathrm{df}$ & CFI & GFI & NFI & RMSEA & SRMR \\
\hline Spring & 3 & 20,000 & 58.25 & 5 & 1.00 & 0.99 & 1.00 & 0.02 & 0.01 \\
\hline \multirow[t]{4}{*}{2009} & 4 & 20,000 & 109.70 & 5 & 0.99 & 1.00 & 1.00 & 0.03 & 0.00 \\
\hline & 5 & 20,000 & 152.66 & 5 & 1.00 & 1.00 & 0.99 & 0.04 & 0.00 \\
\hline & 6 & 20,000 & 88.94 & 5 & 1.00 & 0.99 & 1.00 & 0.03 & 0.01 \\
\hline & 7 & 13,205 & 65.05 & 5 & 0.99 & 1.00 & 1.00 & 0.03 & 0.00 \\
\hline Fall & 4 & 20,000 & 70.17 & 5 & 0.99 & 1.00 & 1.00 & 0.03 & 0.00 \\
\hline \multirow[t]{4}{*}{2009} & 5 & 20,000 & 113.07 & 5 & 1.00 & 0.99 & 1.00 & 0.03 & 0.01 \\
\hline & 6 & 20,000 & 58.18 & 5 & 1.00 & 1.00 & 0.99 & 0.02 & 0.00 \\
\hline & 7 & 20,000 & 88.11 & 5 & 1.00 & 1.00 & 1.00 & 0.03 & 0.00 \\
\hline & 8 & 13,205 & 74.75 & 5 & 1.00 & 1.00 & 0.99 & 0.02 & 0.00 \\
\hline Spring & 4 & 20,000 & 149.51 & 5 & 1.00 & 0.99 & 1.00 & 0.04 & 0.01 \\
\hline \multirow[t]{4}{*}{2010} & 5 & 20,000 & 180.02 & 5 & 1.00 & 0.99 & 1.00 & 0.03 & 0.01 \\
\hline & 6 & 20,000 & 145.66 & 5 & 1.00 & 1.00 & 0.99 & 0.04 & 0.00 \\
\hline & 7 & 20,000 & 128.38 & 5 & 1.00 & 1.00 & 1.00 & 0.04 & 0.00 \\
\hline & 8 & 13,205 & 78.99 & 5 & 1.00 & 1.00 & 0.99 & 0.03 & 0.00 \\
\hline Fall & 5 & 20,000 & 151.35 & 5 & 1.00 & 0.99 & 1.00 & 0.04 & 0.01 \\
\hline \multirow[t]{4}{*}{2010} & 6 & 20,000 & 37.83 & 5 & 1.00 & 1.00 & 1.00 & 0.02 & 0.00 \\
\hline & 7 & 20,000 & 70.91 & 5 & 1.00 & 1.00 & 0.99 & 0.03 & 0.00 \\
\hline & 8 & 20,000 & 102.66 & 5 & 1.00 & 0.99 & 1.00 & 0.03 & 0.00 \\
\hline & 9 & 13,205 & 66.81 & 5 & 1.00 & 1.00 & 1.00 & 0.03 & 0.00 \\
\hline Spring & 5 & 20,000 & 140.04 & 5 & 1.00 & 0.99 & 1.00 & 0.04 & 0.01 \\
\hline \multirow[t]{4}{*}{2011} & 6 & 20,000 & 89.24 & 5 & 1.00 & 1.00 & 1.00 & 0.03 & 0.00 \\
\hline & 7 & 20,000 & 158.49 & 5 & 1.00 & 1.00 & 1.00 & 0.04 & 0.00 \\
\hline & 8 & 20,000 & 201.38 & 5 & 1.00 & 1.00 & 1.00 & 0.04 & 0.01 \\
\hline & 9 & 13,205 & 75.93 & 5 & 0.99 & 1.00 & 1.00 & 0.03 & 0.00 \\
\hline
\end{tabular}


Table 8. Results of comparisons of model invariance of Kansas MAP reading tests across five grades

\begin{tabular}{|c|c|c|c|c|c|c|c|c|c|c|}
\hline $\begin{array}{l}\text { Academic } \\
\text { Calendar }\end{array}$ & $\begin{array}{l}\text { Grade/ } \\
\text { Group }\end{array}$ & Model & $\chi^{2}$ & $\mathrm{df}$ & $\Delta \chi^{2}$ & CFI & GFI & NFI & RMSEA & SRMR \\
\hline Spring & G3-G7 & 1. NC & 67.00 & 25 & & 1.00 & 1.00 & 1.00 & 0.01 & 0.00 \\
\hline \multirow[t]{2}{*}{2009} & & 2. $\mathrm{L}$ & 528.76 & 41 & 461.76 & 1.00 & 1.00 & 0.99 & 0.02 & 0.02 \\
\hline & & 3. LV & 619.04 & 45 & 90.28 & 1.00 & 0.99 & 1.00 & 0.02 & 0.04 \\
\hline Fall & G4-G8 & 1. NC & 29.88 & 25 & & 1.00 & 1.00 & 1.00 & 0.00 & 0.00 \\
\hline \multirow[t]{2}{*}{2009} & & 2. L & 225.73 & 41 & 195.84 & 1.00 & 1.00 & 1.00 & 0.02 & 0.03 \\
\hline & & 3. LV & 258.16 & 45 & 32.44 & 1.00 & 0.99 & 1.00 & 0.03 & 0.04 \\
\hline Spring & G4-G8 & 1. NC & 61.99 & 25 & & 1.00 & 1.00 & 1.00 & 0.01 & 0.00 \\
\hline \multirow[t]{2}{*}{2010} & & 2. L & 509.85 & 41 & 447.86 & 1.00 & 0.99 & 1.00 & 0.04 & 0.03 \\
\hline & & 3. LV & 566.77 & 45 & 56.92 & 0.99 & 0.99 & 0.99 & 0.04 & 0.05 \\
\hline Fall & G5-G6 & 1. NC & 27.54 & 25 & & 1.00 & 1.00 & 1.00 & 0.00 & 0.00 \\
\hline \multirow[t]{2}{*}{2010} & & 2. $\mathrm{L}$ & 333.64 & 41 & 306.10 & 1.00 & 0.99 & 1.00 & 0.03 & 0.03 \\
\hline & & 3. LV & 379.73 & 45 & 46.09 & 1.00 & 1.00 & 1.00 & 0.03 & 0.04 \\
\hline Spring & G5-G6 & 1. $\mathrm{NC}$ & 65.99 & 25 & & 1.00 & 1.00 & 1.00 & 0.01 & 0.00 \\
\hline \multirow[t]{2}{*}{2011} & & 2. L & 353.53 & 41 & 287.54 & 1.00 & 0.99 & 1.00 & 0.03 & 0.03 \\
\hline & & 3. $\mathrm{LV}$ & 487.08 & 45 & 133.54 & 1.00 & 1.00 & 1.00 & 0.03 & 0.06 \\
\hline
\end{tabular}

Note. The levels of model constraints restricted to be equal across grades are: 1. NC: No Constraint (Model structure). 2. L: Factor loading. 3. LV: Factor loading + Factor Variance.

All fit indexes for both Reading and Mathematics tests for different grades and academic years from 10 states satisfied Hu and Bentler's criteria, except RMSEAs and SRMRs for Michigan Mathematics Tests. In summary, the results provide clear support for the metric invariance for all tests except for Michigan Mathematics Tests, and at least, there are configure invariances for all tests.

These results suggest that constructs of MAP tests are well defined, proved to be unidimensional equivalent across grades, and have the same patterns across academic years.

Table 9. Results of comparisons of model invariance of Michigan MAP Mathematics tests across five grades

\begin{tabular}{lllllllllll}
\hline $\begin{array}{l}\text { Academic } \\
\text { Calendar }\end{array}$ & $\begin{array}{l}\text { Grade/ } \\
\text { Group }\end{array}$ & Model & $\chi^{2}$ & df & $\Delta \chi^{2}$ & CFI & GFI & NFI & RMSEA & SRMR \\
\hline Spring & G3-G7 & 1. NC & 1844.03 & 45 & & 0.98 & 0.98 & 0.98 & 0.08 & 0.02 \\
2009 & & 2. L & 3410.3 & 65 & 1566.30 & 0.97 & 0.97 & 0.96 & 0.09 & 0.07 \\
& & 3. LV & 3726.05 & 69 & 315.72 & 0.96 & 0.96 & 0.96 & 0.09 & 0.12 \\
& & & & & & & & & \\
Fall & G4-G8 & 1. NC & 1995.99 & 65 & & 0.98 & 0.98 & 0.98 & 0.08 & 0.02 \\
2009 & & 2. L & 4008.02 & 69 & 2012.02 & 0.97 & 0.96 & 0.97 & 0.10 & 0.08 \\
& & 3. LV & 4328.11 & 45 & 320.10 & 0.97 & 0.96 & 0.97 & 0.10 & 0.13 \\
& & & & & & & & & & \\
\hline
\end{tabular}




\begin{tabular}{lllllllllll}
\hline Spring & G4-G8 & 1. NC & 2628.19 & 45 & & 0.98 & 0.97 & 0.98 & 0.09 & 0.02 \\
2010 & & 2. L & 4699.64 & 65 & 2071.45 & 0.97 & 0.95 & 0.97 & 0.11 & 0.08 \\
& & 3. LV & 152033.9 & 69 & 14734.32 & 0.97 & 0.95 & 0.97 & 0.11 & 0.14 \\
& & & & & & & & & & \\
Fall & \multirow{2}{*}{ G5-G6 } & 1. NC & 3212.61 & 45 & & 0.98 & 0.97 & 0.98 & 0.10 & 0.02 \\
2010 & & 2. L & 3843.60 & 65 & 630.99 & 0.97 & 0.96 & 0.97 & 0.10 & 0.04 \\
& & 3. LV & 4298.94 & 69 & 455.34 & 0.97 & 0.95 & 0.97 & 0.10 & 0.14 \\
& & & & & & & & & & \\
Spring & \multirow{2}{*}{ G5-G6 } & 1. NC & 2705.84 & 45 & & 0.98 & 0.97 & 0.98 & 0.10 & 0.02 \\
& & 2. L & 4254.03 & 65 & 1548.19 & 0.97 & 0.96 & 0.97 & 0.10 & 0.06 \\
& & 3. LV & 4326.35 & 69 & 72.32 & 0.97 & 0.96 & 0.97 & 0.10 & 0.08 \\
\hline
\end{tabular}

Note. The levels of model constraints restricted to be equal across grades are: 1. NC: No Constraint (Model structure only). 2. L: Factor loading. 3. LV: Factor loading + Factor Variance.

\section{Scientific Significance of the Study}

The factor structure of test for a particular grade is directly related to the construct validity interpretation of the test, and validity is one of the most important considerations when evaluating a test. The factor invariance across grades is a fundamental requirement for use in vertical scaling and interpretation of student growth based on the test scores. There are many challenges to providing validity evidence for CAT tests because of its uniqueness compared to fixed form tests. This study using real data provides empirical evidence of construct and invariance construct of MAP scales across grades at different academic calendars for 10 different states. Results show the consistency and reasonableness of interpretation of the MAP RIT scale across grades and academic calendar years for the different states.

\section{References}

Bryne, B. M., Shavelson, R. J., \& Muthén, B. (1989). Testing for equivalence of factor covariance and mean structures: The issues of partial measurement invariance. Psychological Bulletin, 105(3), 456-466. http://dx.doi.org/10.1037/0033-2909.105.3.456

Cella, D., \& Chang, C-H. (2000). A discussion of item response theory and its application in health status assessment. Medical Care, 38 (supplement II), 66-72. http://dx.doi.org/10.1097/00005650-200009002-00010

Embretson, S. E., \& Reise, S. P. (2000). Item response theory for psychologists. Lawrence Erlbaum Associate, Publishers.

Hambleton, R. K. (2000). Emergence of item response modeling in instrument development and data analysis. Medical Care, 38 (supplement II), 60-65. http://dx.doi.org/10.1097/00005650-200009002-00009

Hayes, R. D., Morales, L. S., \& Reise, S. P. (2000). Item response theory and health outcomes measurement in the 21st century. Medical Care, 38(supplement II), 28-42.

Hu, L., \& Bentler, P. M. (1999). Cutoff criteria for fit indexes in covariance structure analysis: Conventional criteria versus new alternatives. Structural Equation Modeling, 6, 1-55. http://dx.doi.org/10.1080/10705519909540118

Loehin, J. C. (2004). Latent variable models: An introduction to factor, path, and structural equation analysis. Mahwah, NJ: Erlbaum.

Lord, F. M. (1977). A broad-range tailored test of verbal ability. Applied Psychological Measurement, 1, 95-100. http://dx.doi.org/10.1177/014662167700100115

Jöreskog, K. G. (1971). Statistical analysis of sets of congeneric tests. Psychometrika, 36, 109-133. http://dx.doi.org/10.1007/BF02291393

Jöreskog, K. G., \& Sörbom, D. (1979). Advances in factor analysis and structural equation models. Cambridge, MA: Abt Books.

Kingsbury, G. G., \& Weiss, D. J. (1983). A comparison of IRT-based adaptive mastery testing and a sequential 
mastery testing procedure. In D. J. Weiss (Ed.), New horizons in testing: Latent trait test theory and computerized adaptive testing (pp. 257-238). New York: Academic Press.

Wilson, M. (2003). On Choosing a Model for Measuring. Methods of Psychological Research Online, 8(3), 1-22

Marsh, H. W., Muthén, B., Asparouhov, A., Lüdtke, O., Robitzsch, A., Morin, A. J. S., \& Trautwein, U. (2009). Exploratory Structural Equation Modeling, Integrating CFA and EFA: Application to Students' Evaluations of $\begin{array}{llllll}\text { University Teaching. } & \text { Structural Equation } & \text { Modeling, } & \text { 16, } & \text { 439-476. }\end{array}$ http://dx.doi.org/10.1080/10705510903008220

McCall, M., \& Hauser, C. (2006). Item Response Theory and Longitudinal Modeling: The Real World is Less Complicated than We Fear. In R. Lissitz, (Ed.), Assessing and Modeling Cognitive Development in School (pp 143-174). Maple Grove, MN: JAM Press.

McArdle, J. J. (1988). Dynamic but Structural Equation Modeling of Repeated Measures Data. In J. R. Nesselroade \& R. B. Cattell (Eds.), The Handbook of Multivariate Experimental Psychology. New York: Plenum Press. http://dx.doi.org/10.1007/978-1-4613-0893-5_17

McDonald, R. P. (1985). Factor Analysis and Related Methods. Hillsdale, NJ: Lawrence Erlbaum Associates.

Northwest Evaluation Association. (2011, January). Technical manual for Measure of Academic Progress \& Measure of Academic Progress for Primary Grades. Portland, Oregon.

Rubin, D. B. (1987). Multiple imputation for nonresponse in surveys. John Wiley \& Sons, New York. http://dx.doi.org/10.1002/9780470316696

SAS Institute Inc. (2008). SAS/STAT ${ }^{\circledR} 9.2$ User's Guide. Cary, NC: SAS Institute Inc.

Steenkamp, J. B., \& Baumgartner, H. (1998). Assessing measurement invariance in crossnational consumer research. Journal of Consumer Research, 25, 78-90. http://dx.doi.org/10.1086/209528

Washington State, on behalf of the SMARTER Balanced Assessment Consortium. (2010). Race to the Top Assessment Program Application for New Grants. Retrieved from http://www.k12.wa.us/SMARTER/pubdocs/SBAC_Narrative.pdf

Way, W. (2006). Online Testing Research: Information and Guiding Transitions to Computerized Assessments. A white paper from Pearson Educational Measurement.

Way, W., Twing, J., Camara, W., Sweeney, K., Lazer, S., \& Mazzeo, J. (2010). Some considerations related to the use of adaptive testing for the Common Core Assessments. Retrieved June 11, 2010, from www.ets.org/s/commonassessments/pdf/AdaptiveTesting.pdf

Wright, B. D., \& Stone, M. H. (1979). Best Test Design. MESA press, Chicago.

Yen, W. (1984). Effects of Local Item Dependence on the Fit and Equating Performance of the Three-Parameter $\begin{array}{llll}\text { Logistic Model. Applied Psychological Measurement, } & 8(2), & \text { 125-145. }\end{array}$ http://dx.doi.org/10.1177/014662168400800201

\section{Appendix A}

\section{CFA Measurement Model}

$$
\mathbf{Y}=\tau+\Lambda \xi+\varepsilon
$$

where $\mathbf{Y}$ is the vector of manifest indicator (goal scores in this study), $\tau$ is a vector of measurement intercepts, $\Lambda$ is the matrix of factor loading, and $\varepsilon$ is a vector of residuals. The model-implied covariance matrix is

$$
\Sigma=\Lambda \Phi \Lambda^{\prime}+\Theta
$$

where $\Phi$ is the latent variable (achievement in this study) covariance matrix and $\Theta$ is the residual covariance matrix. Because we expect the mean achievement will be different across the grades, mean structure is not our concern in this study. In this study, all measurement intercepts were set to zero.

2. CFA Measurement Model in the Multiple Group

$$
\mathbf{Y}^{g}=\tau^{g}+\Lambda^{g} \xi^{g}+\varepsilon^{g}
$$

Where $g$ is group indicator and $g=1,2, \ldots 5$ in this study. $\mathbf{Y}^{g}$ is the vector of manifest indicator (goal scores in this study), $\tau^{g}$ is a vector of measurement intercepts, $\Lambda^{g}$ is the matrix of factor loading, and $\varepsilon^{g}$ is a vector of residuals. 
The model-implied covariance matrix is

$$
\Sigma^{g}=\Lambda^{g} \Phi^{g} \Lambda^{\prime}+\Theta^{g}
$$

where $\Phi^{g}$ is the latent variable (achievement in this study) covariance matrix for group g and $\Theta^{g}$ is the residual covariance matrix for $\mathrm{g}$ group. Because we expect the mean achievement will be different across the grades, mean structure is not our concern in this study and all measurement intercepts were set at zero.

According to many researchers (Bryne, Shavelson \& Muthén, 1989; Jöreskog ,1971; Marsh, Muthén, Asparouhov, Lüdtke, Robitzsch, Morin \&Trautwein, 2009), the invariance of the parameter matrices implied by equation (A.4) means, the covariance matrices for $G$ groups will only be identical if all of the factor loadings, factor variance and covariances, and residual variance are identical across groups. Although there are total 13 partially nested models (named differently for different researchers) can be tested (Marsh et al., 2009) for model invariance. In this study, three invariance tests conducted are: (1) configure invariance (congeneric invariance) without constraint imposed on parameters; (2) weak factor invariance (tau-equivalent or metric invariance) with constraint of equal factor loading; and (3) invariance of factor loading and factor variance. The invariance tested in this study is summarized as following:

1. No constraint, baseline model (NC)

2. Equal factor loadings (L)

$$
\mathrm{H}_{0}: \Lambda^{1}=\Lambda^{2}=\Lambda^{3}=\Lambda^{4}=\Lambda^{5}
$$

3. Equal factor loadings and factor variance (LV)

$$
\begin{aligned}
& \mathrm{H}_{0}: \Lambda^{1}=\Lambda^{2}=\Lambda^{3}=\Lambda^{4}=\Lambda^{5} \\
& \mathrm{H}_{0}: \Phi^{1}=\Phi^{2}=\Phi^{3}=\Phi^{4}=\Phi^{5}
\end{aligned}
$$

